\title{
Activities and Programs for Gifted Students
}

\author{
Peter Taylor and Roza Leikin
}

\section{Introduction: The Aim and the Focal Topics}

The aim of TSG-3 at ICME-12 was to gather educational researchers, research mathematicians, mathematics teachers, teacher educators, designers and other congress participants for the international exchange of ideas related to identifying and nourishing mathematically gifted students. The focal topics presented at the TSG-3 included but were not restricted to theoretical models of giftedness, the relationship between creativity and giftedness and the empirical research that will contribute to the development of our understanding in the field. Participants discussed effective research methodologies and research innovations (e.g., brain research) in the field of mathematical giftedness; the findings of qualitative and quantitative studies related to high mathematical promise, its realization, and the relationship between mathematical creativity and mathematical talent. Additional attention was given to the profiles of the gifted child: their range of interests, ambitions and motivations, social behaviour, how and at what age their giftedness is discovered or developed.

Educators who participated in TSG-3 discussed instructional design directed at teaching the gifted as well as development of appropriate didactical principles. The discussions were focused on the ways that lead students to discover and realize their

Organizers Co-chairs: Peter Taylor (Australia), Roza Leikin (Israel); Team members: Viktor Freiman (Canada), Linda Sheffield (USA), Mihaela Singer (Romania), Bo Mi Shin (Korea); Laison IPC Member: Shiqi Lee (China).

\author{
P. Taylor $(\bowtie)$ \\ University of Canberra, Canberra, Australia \\ e-mail: pjt013@gmail.com \\ R. Leikin \\ University of Haifa, Haifa, Israel \\ e-mail: rozal@edu.haifa.ac.il \\ (C) The Author(s) 2015
}

S.J. Cho (ed.), The Proceedings of the 12th International Congress

on Mathematical Education, DOI 10.1007/978-3-319-12688-3_28 
mathematical talents, and the ways of developing mathematical innovation at high level. The participants discussed mathematical activities that are challenging, free of routine, inquiry-based, and rich in authentic mathematical problem solving; types of mathematics suitable for challenging gifted students; creation of mathematics challenges; out-of-school ways of fostering giftedness, e.g., mathematics clubs, mathematical shows and competitions.

Last but not least we paid attention to teacher education aimed at mathematics teaching that encourages mathematical promise and promotes mathematical talents, including issues of the psychology of teaching talented students, socio-cultural and affective characteristics of the mathematically gifted, and the types of mathematics and pedagogy suitable for educating teachers of gifted students.

Participants took part in four sessions. Three sessions $(1,2$, and 4$)$ were devoted to research and project presentations and the discussions based on these presentations. Session 3 was organised with round table presentations. In what follows we present main topics of the sessions and some examples of the studies and projects presented at the TSG-3 at ICME-12.

\section{Examples and Main Insights}

\section{Opening the Discussion}

Session 1 was devoted to introduction to the central topics of the TSG. Three lectures, by Linda Sheffiled, Roza Leikin and Alexander Soifer, opened three main reviews of the TSG: international projects for realisations of students' mathematical potential with special emphasis on high mathematical potential (REF), systematic research on characterisation of mathematically gifted students, and mathematics for mathematically gifted.

Linda Shefield's talk "Mathematically Gifted, Talented, or Promising: What Difference Does It Make?" stressed the importance of the developmental perspective of mathematical abilities and the importance of providing each and every student with oportunities to realise these abilities. Based on the position that science, technology, engineering, and mathematics (STEM) are critical to the economy, security, and future of the world, Linda Sheffield argued that we need students who will become adults who understand the complexities of a technological world, who ask the essential questions to safeguard that world, and who will become the leaders, researchers and innovators in the STEM fields of the future. According to Sheffield, too often, in the United States, these students go unrecognized, unmotivated, and under-developed at a time when they are most vital. Sheffield discussed in her presentation whether the way we historically define these future STEM leaders and innovators has an effect upon their growth and development. This talk served as a starting point to the discussion of the international project devoted to the realization of students' intellectual potential related to STEM. 
Roza Leikin stressed the importance of conducting systematic and well-designed research on the characteristics of mathematically gifted students. She presented large-scale Multidimensional Examination of Mathematical Giftedness that she conducts with colleagues from the research group in the University of Haifa (Mark Leikin, Ilana Waisman, Shelley Shaul). The presentation was devoted to brain activity (using ERP- Event-Related Potentials - methodology) associated with solving mathematical problems that require transition from a geometrical object to a symbolic representation of its property. Some 43 right-handed male students with varying levels of general giftedness (Gifted-G, Non-gifted-NG) and of mathematical expertise (Excelling-E, Non-excelling-NE) took part in the study. The researchers aimed to investigate the differences in brain activation among four groups of participants (G-E, G-NE, NG-E, and NG-NE). The findings demonstrated different patterns of brain activity associated with problem solving among the four experimental groups. In educational practice the results suggest that different groups of the study population need specific instructional approaches to realize fully their intellectual potential.

Alexander Soifer claimed that mathematics cannot be taught, it can only we learned by our students while doing it. According to Soifer, the classroom ought to be a laboratory where students actually touch the subject, overcome difficulties, which we sometimes call problem solving. "What kind of problems?"- -asked the author, and answered: "here comes Combinatorial Geometry!" It offers an abundance of problems that sound like a "regular" school geometry, but require for their solutions synthesis of ideas from geometry, algebra number theory, and trigonometry and thus they are rich, challenging and insightful, and thus appropriate for the education of mathematically talented individuals.

When the three presenters finished their presentations it became clear that the contrast between the presentations enlightened the importance and openness of the following questions: Who are the mathematically gifted? Can giftedness be developed or rather is it realized? How do different perspectives on giftedness determine research and practice in the education of the mathematically gifted? and What kinds of mathematics problems are most appropriate to mathematically gifted?

\section{International Experiences and Projects for Gifted}

The second session was devoted to the projects of different kinds directed at educational activities with mathematically advanced students.

Mark Saul described activities of the Center for Mathematical Talent (CMT) at the Courant Institute of Mathematical Sciences (New York University) which was organized in the fall of 2010. Its mandate is to identify and support mathematically talented students in and around the New York City area-especially those from backgrounds where such services have traditionally been weak. The goal at the CMT is to create institutions, materials, and practices that will unlock and nurture 
these abilities in students, and will have an impact both on their lives as individuals and on the society in which they live.

Ildar Safuyanov reported on the experiences of fostering creativity of pupils in Russia. While the creative approach is understood by the authors and his colleagues as certain abilities and readiness of a person for creating something new, the purpose of educational process at school is the education of a person who would use a creativity approach for solving scientific or practical problems and for thinking independently. According to Safuyanov, differentiated teaching is an effective way of promoting creativity in conditions. Ildar Safuyanov discussed and compared different types of differentiated teaching and provided the audience with examples of internal differentiation by level of mathematical tasks.

Abraham Arcavi presented the Math-by-Mail project which is an online, interactive, extracurricular enrichment program in recreational mathematics conducted by mathematics educators from the Weizmann Institute of Science in Israel (leaders- Yossi Elran, Michal Elran, Naama Bar-On). Participants of the Math-by-Mail project are engaged in a multi-sense learning experience involving many skills such as comprehension, solving enquiry based problems and correspondence with mathematicians. The lecture demonstrated the scope of the program, its pedagogical and technological characteristics and its benefits for the talented math student.

Viktor Freiman from the University of Moncton, Canada, shared his innovative experience of designing and conducting professional learning communities with inclusive practices for students who "already know". In his project, mathematically gifted and talented students contribute to the virtual community. Same research findings demonstrated the effectiveness of the suggested approach as well as its complexity.

Duangnamol Tama reported on the project named "The Development and Promotion of Science and Technology Talented Project (DPST)". The project is supported by the the Thailand government. Thus national education focuses its efforts and policies on the national development of science, mathematics, and technology through the promotion of high caliber students in these areas.

At the end of this session the participants were exposed to the variety of approaches and variety of ideas directed at promotion of the mathematically gifted. Further discussion between the participants of the session was directed at answering the questions: Which features of the programs for mathematically gifted are culturally dependent and which of them are intercultural? Can successful projects from one country be applied in another country with a different cultural heritage? Do inclusive programs suit needs of the gifted?

\section{Didactical Approaches and International Perspectives}

At Session 3 participants of the TSG-3 were exposed to different didactical approaches and international perspectives on the education of mathematically advanced students. This was a round tables session. The authors were provided with 
an opportunity to present their papers several times to different people who were interested in their presentations. The groups changed each $10 \mathrm{~min}$ and each participant had an opportunity to learn about several works presented at this session. These works included:

- The program of making students create math problems: One of the methods of developing students' abilities to think and express by Nobuo Itoh from Japan,

- The role of student motivation in developing and assessing the acquisition of higher-order thinking skills, by Vincent Matsko, USA

- How the mathematically gifted and talented senior primary school students in Hong Kong understand mathematics, by Wai Lui Ka, Hong Kong

- The research on the mode of motivating the gifted students, by Wang He Nan, Beijing

- Enhancing mathematical research in high school, by Laura Morera, Spain

- Mathematical creativity and attachment theory: an interdisciplinary approach for studying the development of mathematical creativity of preschool children with a precarious childhood, by Melanie Münz, Germany.

- Problem modification as an indicator of deep understanding, by Mihaela Singer Florence, Romania

- Little University of Mathematics, by Laura Freija, Latvia

- Effects of Modified Moore Method on Elementary Number Theory for Gifted High School Students: An Exploratory Study, by Hee Kyoung Cho, Korea,

- Korean Middle School Student's Spatial Ability and Mathematical Performance: Comparison between Gifted Students and General Students by Sungsun Park, Korea

These presentations ended up with multiple questions about the research conducted by different participants and the practices implemented in different countries. The need for the better connections between theory and practice become more and more clear. Following this session we ask: What research approaches can inform us in the best way? How does research methodology depend on definition of gifted chosen in the study? How research and practice can be interwoven to advance theories of mathematical giftedness and advance effectiveness of the practical projects for mathematically gifted students.

\section{Characteristics of Mathematically Gifted Students}

The fourth session of the TSG focused on characterization of mathematically gifted students.

BoMi Shin from South Korea reported on a study that provided probability tasks to mathematically gifted students to investigate analogical reasoning as it emerges during the problem-solving process of students. Atsushi Tamura from Japan presented a case study about a gifted high school student in which he identified 5 
prominent characteristics in thinking processes by investigating how he devised mathematical proof. Furthermore, this study found that sharing the thinking process of the gifted in the classroom had a good effect on both the class and the gifted himself.

Amaral Nuno and Susana Carreira from Portugal described analysis of creativity in the problem solving processes presented by eight students (from grades 5 and 6 , aged between 10 and 11) who have participated in and reached the final phase of a Mathematical Competition. They suggested ways for evaluation of students' creativity in mathematical problem solving in a situation that includes a competitive factor and takes place beyond the mathematics classroom, which is often seen as restrictive for the development of mathematical creativity.

Brandl Matthias from Germany (in collaboration with Christian Barthel) suggested that there are two ways of selecting promising students for the purpose of fostering (in mathematics): whereas the standard procedure is to offer additional courses or material for volunteers or those chosen by the teacher, the other and perhaps more elitist - but with respect to quantitative aspects easier-way is to select the students with the best marks. Brandl argued that from a psychological perspective these ways represent two opposite sides of the causality between giftedness and assessment. One result of this investigation is the finding of strong correlations between the profiles of mathematical interests of specific subgroups that fulfill the characteristics which define mathematical giftedness.

The lecture by Marianne Nolte discussed relationships between "High IQ and High Mathematical Talent!". The findings followed from the long-term PriMaProject in the University of Hamburg. This project is a research project and a project for fostering mathematically talented children. To detect among them mathematically especially talented children demands a highly comprehensive search for talents. Marianne Nolte stressed the complexity of the evaluation of mathematical talent and stressed that search for talent poses the risk that children may be classified wrongly as especially talented or that children's talents are not recognised.

In conclusion the following questions were raised by the group: Do we know more than Krutetskii after we perform studies on characteristics of students with high mathematical abilities? How do researchers choose their research paradigm? How do research methodologies correspond to the students' age or to a specific characteristic of giftedness that is examined? How studies on students thinking can/should inform educational practices?

The work of the group demonstrated how much is done in the field of the education of mathematically advanced students but moreover it stressed how much should be done in order to get a better understanding of the phenomena of mathematical giftedness and the effective ways of realization of mathematical potential in all students including mathematically talented ones. 
Acknowledgments We would like to thank all the participants for their interest in the topic, all the contributors for their interesting presentations and hard work at this TSG, Team membersViktor Freiman, Linda Sheffield, Mihaela Singer, Bo Mi Shin-for fruitful collaboration in preparation and conducting this TSG.

Open Access This chapter is distributed under the terms of the Creative Commons Attribution Noncommercial License, which permits any noncommercial use, distribution, and reproduction in any medium, provided the original author(s) and source are credited. 